\title{
Trial halted after gene shows up in semen
}

Nell Boyce, Washington

A patient in a gene-therapy trial has had the virus used to transfer the gene show up in his semen. The finding highlights the danger that gene therapy may inadvertently modify the genetic make-up of a patient's children.

The discovery was made in a trial at the Children's Hospital of Philadelphia, conducted in collaboration with researchers at Stanford University Medical Center in California. Officials at the Food and Drug Administration (FDA) halted the trial.

But the Recombinant DNA Advisory Committee (RAC), which advises the FDA on the safety and ethics of such experiments, announced on 6 December that the trial could continue, subject to special monitoring. The FDA is expected to follow this advice.

Gene therapy often uses viruses to transport therapeutic genes into cells. But these viruses can become widely dispersed in the body, and animal studies have shown that they can end up in the ovaries and testes. The FDA, which regulates clinical trials in the United States, has been concerned that the therapeutic genes might be passed on to future generations. In 1998 it ruled that many human gene trials that ran the risk of contaminating eggs or sperm could enrol only sterile patients. The rule exempted trial participants whose lives were in immediate danger, but covered trials for treatable diseases.

Some scientists and patients' groups have argued that this impedes research while protecting against what they consider to be a very small risk. No animal studies have shown gene transmission to the next generation; researchers suspect that evolution has devised ways of protecting the genetic cargo of eggs and sperm from viral onslaught.

As a precaution, the FDA requires investigators to test the semen of men taking part in trials where preclinical animal research has detected the gene in the gonads. That was the case in the Stanford study, which put the human gene for blood-clotting factor IX into the livers of men with severe haemophilia.

Mark Kay, one of the geneticists leading the study, says that the 63-year-old patient received a low dose of a virus carrying the gene on 13 August. Tests on his semen subsequently detected gene sequences from the virus. This result persisted for seven weeks.

But it is not known whether the virus actually entered the sperm, as semen also contains other cell types such as white blood cells. To investigate this possibility, Kay's colleagues separated a semen sample into its constituent cell types and identified the cells containing virus gene fragments. The sperm itself tested negative.

The FDA has said that no additional patient can be enrolled in the trial until each patient's semen tests negative for three

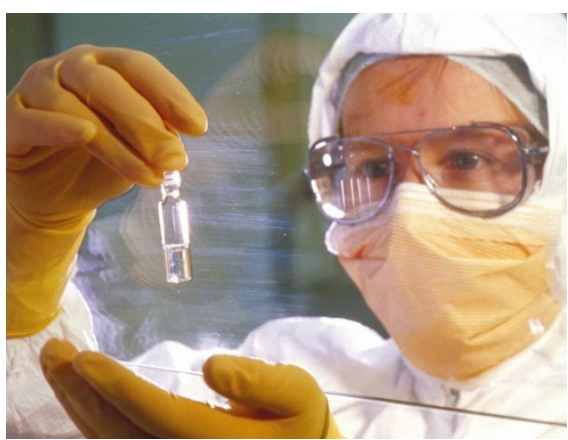

Hopes and fears: could a therapeutic gene be inadvertently passed on to future generations?

months - the time it takes for sperm to mature. But Kay's team plans to enrol nine patients in the trial one after the other, so this could extend it for up to five years, Kay asserts. He says the risk of children being affected is reduced because patients are advised to use condoms. "If you look at the realm of other risks that people take in drug studies, this one is relatively small," he says.

The RAC has agreed, recommending that the trial be allowed to continue, provided researchers conduct frequent tests on isolated cell types from patients' semen samples.

The ethical issues will deepen only if researchers find that an effective gene therapy also shows up in sperm. "We're dealing here with the grey area in which you may knowingly allow something but not deliberately do it," says Ruth Macklin, a bioethicist at the Albert Einstein College of Medicine in New York, and a member of the RAC.

\section{Need for vaccine stocks questioned}

\section{Erika Check, Washington}

US biodefence experts are divided this week over a research paper that calls into question a government decision to spend hundreds of millions of dollars on smallpox vaccine.

The paper's authors say that $\mathbf{4 0}$ million doses of vaccine is enough to protect the country from a terrorist attack. Published in the current issue of Emerging Infectious Diseases $(7,959-969 ; 2001)$, the paper was written by Martin Meltzer, an economist at the Centers for Disease Control and Prevention (CDC) in Atlanta, Georgia, with J. Donald Millar, who led the CDC's effort to eradicate smallpox, and two CDC biologists.

Health secretary Tommy Thompson announced on 28 November that the United States will buy 155 million doses of vaccine from Acambis, a British firm, for $\$ 428$ million, bringing the total effective US stockpile to 286 million doses.

Government scientists defended the purchase. Donald Henderson, who led the global effort to eradicate smallpox and now advises Thompson on biodefence, suggests the authors were influenced by the CDC's earlier decision to hold 40 million doses.

"Amazingly, they reached the conclusion that this indeed was the correct number to purchase," Henderson says.

Other researchers dispute the paper's assumption that every patient would infect an average of three others. Steve Leach and Raymond Gani, of Britain's biological weapons laboratory at Porton Down near Salisbury, report in Nature this week (pages 748-751) that each smallpox patient is likely to infect from 3.5 to 6 others, and even more initially, because people now lack immunity to the disease, which was eradicated worldwide in 1976.

But Meltzer says his team's work was rigorous. "As researchers, my colleagues and I try to approach the analysis of each and every problem in a neutral fashion, employing scientific procedures," he says.

There is concern that stockpiling vaccine is a waste of scarce public-health resources, as a move to vaccinate the entire US population would result in hundreds or thousands of deaths from side effects. But some officials who agree the stockpile may not be needed argue that it still reassures the public. "It may be politically necessary and prudent to make sure that we allow a large safety margin," says Stephen Morse, director of the Center for Public Health Preparedness at Columbia University in New York.

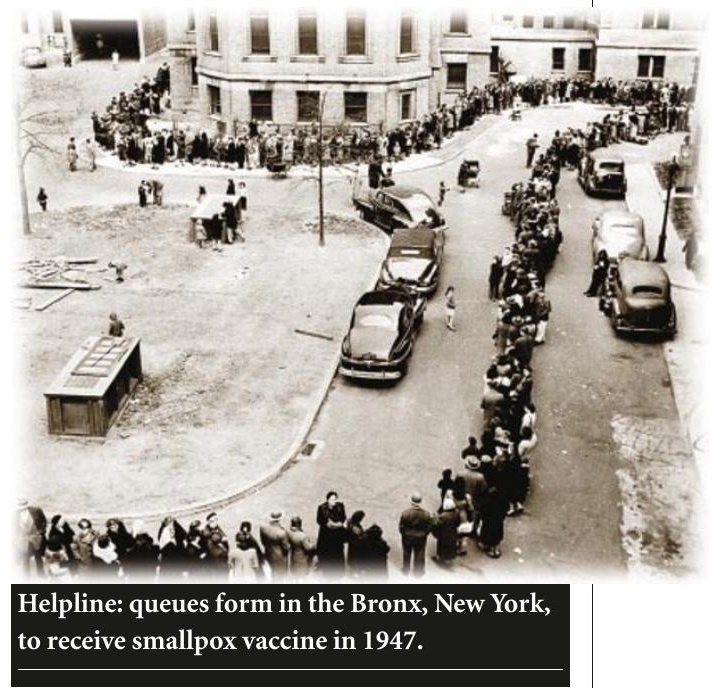

